\title{
Physiotherapy ANd Low BACK PAIN - PART III: OutCOMES RESEARCH UTILISING THE BIOPSYCHO- SOCIAL MODEL: PSYCHOSOCIAL OUTCOMES
}

\begin{abstract}
A comprehensive understanding of low back pain (LBP) has evolved that necessitates the use of a biopsychosocial model, focusing on illness rather than disease and incorporating the biological, psychological and social aspects that are important to understand and to study LBP in its chronic form. Traditional outcome measures that measure elements within the biological component are limited to assess the spectrum of impacts caused by chronic low back pain (CLBP) and the validity, reliability and sensitivity of some of these measures has been questioned.

\author{
B.Sc. (Physio.), Cert OMT (SA), \\ M.Sc. (Physio.) ${ }^{1}$
}

BARDIN D,

1 University of Stellenbosch, South Africa. Current appointments: Private practitioner, Park Orchards Physiotherapy and Ringwood Physiotherapy and Spinal Clinic, Melbourne, Australia. Few physiologic tests of spine function are clinically meaningful to patients, objective physical findings can be absent, and in CLBP disability and activity intolerance are often disproportional to the original injury. Biological outcomes should be complemented by outcomes of the psychosocial aspects of back pain that measure the considerable functional and emotional impact on the quality of life of patients experiencing low back dysfunction. Outcomes research is an analysis of clinical practice as it actually occurs and can make a valuable contribution to understanding the multidimensional impact of LBP. Psychosocial aspects of the biopsychosocial model for outcomes research are discussed in part III: functional status/disability, psychological impairment, patient satisfaction, health related quality of life.
\end{abstract}

KEY WORDS: OUTCOMES RESEARCH, LOW BACK PAIN, BIOPSYCHOSOCIAL MODEL, OUTCOME MEASURES, FUNCTIONAL STATUS, DISABILITY, PSYCHOLOGICAL IMPAIRMENT, PATIENT SATISFACTION, HEALTH RELATED QUALITY OF LIFE

\section{INTRODUCTION}

The enormous costs to health budgets as a result of high recurrence rates (Croft et al 1997) and increased chronic incapacity (Taimela et al 1997) associated with LBP is widely acknowledged; it places a responsibility on the physiotherapy profession to respond positively to the challenge of analysing the quality and cost of physiotherapy management of LBP (Bardin 2002a). Providers of healthcare treating patients with LBP are increasingly being held accountable for standards of care and selection of treatment intervention (Bardin 2002a;

\section{CORRESPONDENCE TO:}

Lynn Bardin

Park Orchards Physiotherapy

616 Park Road

Park Orchards

Victoria 3134

Australia

Tel: 9-6-13-98761964

Fax: 9-6-13-98790711

E-mail: lynnbardin@yahoo.co.uk
Huijbregts et al 2002 ). It has been suggested that the diligent documentation of the outcome of care provided in clinical practice is an attainable goal for everyday clinicians that will enable physiotherapists to measure change and to make a contribution to the demand for evidencebased practice in the field of LBP management (Bardin 2002b).

Much published research on LBP has utilised a biomedical model of health and tissue dysfunction that focuses on disease/tissue pathology rather than on illness (Bardin 2002b; Jones et al 2002). Clinicians have learned that measures of physical/biological impairment are not sufficient for assessing outcome as they have been found to correlate poorly with the patient's subjective function (Mayer et al 1989; Hagg et al 2002). Patients with CLBP and disability face complex biopsychosocial problems, hence a multifactorial model of illness is particularly pertinent to the study of LBP (Bardin 2002b).

Outcomes research, emphasising patients' assessments of pain, function, quality of life and satisfaction with the results of the intervention, is a feasible and affordable analysis of the outcome of healthcare (Bardin 2002a). Psychosocial outcome measures (such as measures of disability, distress, depression and health-related quality of life) complement measures from the biological component (measures of pain and movement dysfunction) that have been deemed to appropriately capture the broad impact of LBP, in particular CLBP, on patients' quality of health (Bardin 2002b). It is therefore important that clinically appropriate, valid, reliable and responsive outcome measures (Liang 2000; Stratford et al 2002) from this aspect of the biopsychosocial model are selected, included and, where lacking, developed, to document the effect of physiotherapy management of this costly and potentially disabling condition (Bardin 2002b).

\section{FUNCTIONAL STATUS/ DISABILITY}

Reduction in pain, improvement in function and prevention of disability are 
core aspects of physiotherapy management of LBP (Bardin 1998, 2002a and $2002 b$ ). Therefore in the quest for evidence of effective treatment for LBP it is important that physiotherapists utilise measurement tools that accurately assess function/disability and that are valid to monitor change in functional status over time. Hagg and colleagues suggest that role function presents in easy to measure 'hard facts' such as work status or days off work and is easily controlled (Hagg et al 2002). The functional restriction/ disability of the LBP patient, however, is expressed as the patient's self-report of symptoms, behaviour or 'inability to do' in activities of daily living (ADL). Sometimes viewed as 'soft'/subjective, these outcomes are in fact considered very important in patients with LBP (Deyo and Diehl 1983) and it has been argued that the crucial attribute of 'hardness' is simply reliability or reproducibility of a finding (Feinstein et al 1986). It has been suggested that the validity of any outcome measure can be considered only as a patient- or clinician-based judgment concerning the usefulness of items in an outcome instrument (Deyo et al 1994; Marx et al 1999).

There are numerous questionnaires that aim to measure activity limitations in people with LBP. Questionnaires such as the Quebec Back Pain Disability Scale (Kopec et al 1995), SF-36 Physical Functioning Scale (Ware and Sherbourne 1992), Roland Morris Disability Questionnaire (RMQ) (Roland and Morris 1983a and 1983b), Aberdeen Back Pain Scale (Ruta et al 1994), Oswestry Disability Index (ODI) (Fairbank et al 1980), Back Pain Functional Scale (Stratford et al 2000) and Spinal Stenosis Questionnaire (Stucki et al 1996) have been reported to be highly valid measures of functional status that accurately assess activity limitation in LBP patients (Deyo and Diehl 1983; Bardin 1998, 2000a and 2000b). Research of LBP has often lacked rigour and, although research in outcome of treatment for LBP has developed greatly in recent years (Deyo et al 1994; Bouter et al 1998; Hagg et al 2002), there is no recognised gold standard for attributes such as disability or change in functional status (Stratford et al 2000; Hagg et al 2002). One of the areas of concern to researchers is that therapists need to know when change in an observed score indicates that real change has occurred (Davidson and Keating 2002). This change, called the 'minimum detectable change' (MDC) has been defined as the amount of change required to be $90 \%$ confident that an observed change in scores reflects real change in the underlying variable (Stratford et al 1996).

General measures of health, such as the SF-36 health profile (Ware and Sherbourne 1992) acknowledge there are many different aspects of health. The SF-36 has been found to be valid and reliable (Ware and Sherbourne 1992; McHorney et al 1992). Of importance is its potential as a measure of successful treatment for back pain patients (Lansky et al 1992). The SF-36 is, however, a generic questionnaire and a conditionspecific questionnaire is likely to be more sensitive to clinically significant changes in general health status over short periods (Ruta 1994).

The ODI and the RMQ have existed for more than two decades and have emerged as the most commonly recommended condition-specific outcome measures for LBP (Deyo et al 1998; Stratford et al 2000). It has been suggested that these first-generation measures are as good as or better than more recently developed tools (Stratford and Binkley 1997) that have had the benefit of research developments in the field of outcome assessment. The ODI, although widely used as a questionnaire, has met with criticism with regards to its validity (Walsh 2000). Good validation studies should state a clear hypothesis and test it using a rigorous design and statistical analysis (Ware 1987; Streiner and Norman 1995; Stratford et al 2002). In this regard it has been suggested that the ODI has not been developed with good psychometric properties and is not a gold-standard measure (Walsh 2000). Stratford et al (2000) were of the opinion that, in fact, there is no objective gold standard for comparison of functional status questionnaires. Frost et al (2000) suggested that more research is necessary to assess the responsiveness and minimally important change in scores on the ODI (Streiner and Norman 1995; Deyo et al 1998) and in more recent research Davidson and
Keating (2002) reported that there has been no reporting of MDC for the modified ODI and Quebec questionnaires or the SF-36 physical health scales. These authors, suggested, however, that one of the advantages of the ODI is that there is sufficient 'scale width' so that initial scores are far enough on to the scale to allow detection of change in scores over time (Davidson and Keating 2002). The research by Davidson and Keating (2002) emphasised scale width as an important attribute to reliably detect change over time.

The RMQ has been subject to more rigorous research, there is a large volume of evidence reported in the literature on the reliability of the RMQ (Riddle and Stratford 2002), the MDC has been established (Stratford et al 1996) and this questionnaire has been found to correlate well with original pain scales and spinal flexibility (Deyo 1986; Bardin 1999). Internal consistency, reproducibility and reliability are important for self-administered questionnaires and the RMQ has been found to be as reproducible and valid, and in fact, more responsive to changes over time than the complete Sickness Impact Profile (SIP) from which it was drawn (Deyo 1984). The RMQ, ODI and Jan van Breenen Institute Pain and Function questionnaires were compared to detect change over time and the RMQ was found to be the preferred instrument for assessing change over time in patients with LBP (Stratford et al 1994). Furthermore the RMQ and has been found to be better than the Aberdeen Back Pain Scale (Ruta 1994) to measure differences between different groups of patients on variables relating to activity limitations, medication and co-morbidity (Garratt et al 2001). The Aberdeen Back Pain Scale is a condition-specific questionnaire that was tested according to the rigorous procedure recommended by Streiner and Norman (1995) and validated against the SF-36. The study by Garratt et al (2001) supports earlier research that the RMQ is one of the preferred tools for measuring change in functional status of LBP patients over time. The RMQ has been reported to be superior to other LBP measures of disability (Deyo 1984; Stratford et al 1994; Deyo et al 1998) and recent research 
criticising the RMQ (Davidson and Keating 2002) is the exception and contrary to the large body of evidence reported in the literature on the reliability of RMQ scores (Riddle and Stratford 2002). The RMQ is the LBP disability questionnaire recommended for use together with other outcome measures for outcomes research of LBP (Deyo et al 1998) and has been used for comparison with other newer scales to assess their usefulness (Stratford et al 2000).

Recent research has led to the development of the Back Pain Functional Scale, which is a self-report functional status measure appropriate for clinical practice and clinical research (Stratford et al 2000). The BPFS, based on the World Health Organisation's (WHO) model of impairment, disability and handicap (WHO, ICF 2001), was developed from a sound theoretical framework (by researchers with extensive experience of the RMQ). In a recent study comparing the BPFS with the RMQ it was found that the BPFS was superior to the RMQ with respect to four areas: ceiling effect, variation in a patient's score, minimal detectable change and sensitivity to change (Stratford et al 2000). The BPFS is easy to administer and score, has excellent prospects for clinical use and has a small but consistent advantage over the RMQ, particularly when the measures are considered for individual patient application (Stratford and Binkley 2000).

A condition-specific functional status questionnaire for the assessment of lumbar spinal stenosis patients was developed by Stucki et al (1996) and has been cited as a model for development of functional and satisfaction measures (Carey 1996). This questionnaire has been found to be reproducible, internally consistent, valid and highly responsive. Furthermore it specifically addresses the symptoms and function deficits characteristic of the neuro-ischaemia syndrome associated with spinal stenosis and tests the measurement properties of symptom severity, physical function and satisfaction scales in patients undergoing decompressive surgery (Stucki et al 1996). These outcomes directly reflect the goals of the intervention and thus have the greatest face validity and credibility to patients and physicians. Appropriate attention has been paid to issues of validity, reliability, responsiveness, brevity and clinical utility and Carey is of the opinion that the excellent measurement properties of this outcome measure are combined with very good prospects for practical utility (Carey 1996).

Rothstein (2001) emphasises the importance of respecting what the patient values and Moore and Jull (2002) suggest that within the patient-therapist relationship there has been a shift towards more patient focused treatment leading to patient empowerment. Patients tend to define their problems in terms of disablities or handicaps (WHO, ICF 2001) rather than impairments (Partridge 1984; Bardin 2003). Rothstein (2001) urges us to consider what patients find to be most critical in their lives and it has been suggested that outcome should be measured in relation to what patients perceive as their problems (Yekutiel 2002; Bardin 2003). The Patient-Specific Functional Scale (Stratford et al 1995) might provide a useful assessment of outcome in this regard. In some cases the patient's definition of their problem, expressed in their own qualitative description, will enable the physiotherapist to focus on patient-specific goals. For example, recent research documents an elite athlete's rapid and successful rehabilitation (following L4-S1 instrumented lumbar spinal fusion), return to a successful running career and $100 \%$ patient satisfaction with the outcome (Bardin 2003). The athlete was particularly focused on what she perceived as her disability (inability to run painfree) and her handicap (unable to participate in running events). Baker et al (2001) suggest that physiotherapists should identify patients' goals and objectives in order to maximise outcomes. The patient's expressly stated goal was to return to painfree running at competition level and illustrates the importance of understanding the desired outcome from treatment as specifically defined by the patient (Bardin 2003).

\section{PSYCHOLOGICAL IM PAIRMENT}

It has been suggested that the major problem, in chronic pain, lies in the interpretation of psychological impair- ment (Waddell et al 1993). The affective dimension of chronic pain in the CLBP patient presents clinically as psychological distress in the form of anxiety, increased somatic awareness and depressive symptoms (Waddell and Main 1984). Waddell and colleagues were of the opinion that, in the absence of proportionate physical, psychosocial or psychological impairment, disability due to CLBP requires further exploration of the patient's cognitions and pain behaviour (Waddell et al 1993). They suggested that low back disability must depend on other factors than solely the severity of pain or objective physical impairment. Their view is supported by other reports that socio-economic and work-related factors may be better determinants of low back disability than either biological or medical factors (Bigos et al 1991; Volinn et al 1991).

It appears to be important that studies of CLBP should include measures of psychological impairment in order to capture this aspect of the multidimensional impact of CLBP on the lives of patients with low back disability. There are a number of measuring tools that have been reported to be useful to document psychological impairment in CLBP patients. The scaled version of the General Health Questionnaire (Goldberg and Hillier 1979) is wellvalidated and can be used as a measure of general psychological status (Goldberg 1985). This questionnaire measures four elements of distress: depression, anxiety, social impairment and hypochondriasis. It is scored on a 0-90 scale with a score in excess of 39 considered to be associated with psychological symptoms. In a study by Frost et al (2000) $39 \%$ of patients with CLBP who enrolled in a functional restoration programme scored greater than 39 on the General Health Questionnaire. It is possible that scores from the General Health Questionnaire will be useful to guide and direct physiotherapy management of CLBP, which increasingly emphasises challenging the belief system of patients with CLBP and channeling them into an appropriate active rehabilitation programme where the patient becomes an agent of his/her own healing (Bardin 1998 and 2000c). 
There is a well recognized association between CLBP and depression, which may proceed or follow the development of LBP (Levy et al 2002), and the outcome of treatment is likely to be influenced by a state of depression. Hence documentation of this aspect of the CLBP patient's mental health is important in the study of the multidimensional impact of CLBP on their health. The Beck Depression Inventory (BDI) (Beck et al 1961) has been used to evaluate change in mental health status of CLBP patients (Brown et al 1999). Wesley et al (1999) evaluated the accuracy of the BDI in assessing CLBP. They concluded that the BDI could be used to generate important information about the severity of interference posed by pain on the functioning of an individual, while allowing for an independent evaluation of subjective indices of depression and somatic disturbances.

Recent research by Levy and colleagues found that a three-question depression screener is shorter, easier to administer and easier to score than the BDI (Levy et al 2002). A positive response to the three-question depression screener was associated with higher symptom intensity and with poorer functional status and health-related quality of life as measured by the SF-36. The three-question screener researched by Levy et al (2002) has demonstrated specificity exceeding $90 \%$ and a sensitivity of $83-94 \%$ for detecting depression (Rost et al 1993). It appears to be a quick and reliable measure for detecting/identifying depression, however does not lend itself to measuring change over time associated with treatment for LBP. It would appear wise to identify depression using the three-question depression screener (Fig. 1) (Levy et al 2002). In the research by Levy et al (2002) a positive response to either Question 37 or Question 39 on the Health Status Questionnaire was considered a 'positive depression screener'. The response to Question 38 had no impact on the result of the depression screener. All patients were categorised as having either a 'positive' or 'negative' depression screener response (Levy et al 2002). In outcomes research of LBP it would appear judicious that patients who have a positive depression screener response (Levy et al 2002) should be further evaluated using a standardised self-report measure such as the BDI to measure depression and to document change in this variable.

The modified Zung Depression Inventory (ZUNG) (Zung 1965) measures depressive symptomatology on a 23-item scale (Main et al 1992) and is a validated psychometric questionnaire (Mannion et al 1996); however it has been reported as manifesting less specificity and sensitivity than the ODI, Million Scale (Million et al 1982) or General Function Score (Hagg et al 2002). It would appear that use of the ZUNG questionnaire should not be equated with functional status questionnaires and psychological questionnaires should rather be seen as providing a different but necessary dimension to the outcome analysis.

The modified somatic perception questionnaire (MSPQ) (Main 1983; Deyo et al 1989) is another validated psychometric questionnaire. Adams et al (1999), in assessing personal risk factors for first-time low back pain, found that the sum of the scores from the ZUNG and MSPQ questionnaires was the best psychometric predictor. The total score from these questionnaires (ZUNG + MSPQ) has a particularly high specificity and sensitivity for predicting psychological disturbance in LBP (Greenough and Fraser 1991; Main et al 1992).

The Health Locus of Control (HLC) (Wallston et al 1976 and 1978) is a validated psychometric questionnaire that assesses personal characteristics such as depressive feelings and anxiety, rather than work-related factors (Adams et al
1999). It is a theoretical construct which has been used in research and in the study of CLBP patients (Härkäpää et al 1991) and is divided into three subsections concerned with 'internal' factors (IHLC), 'powerful others' (PHLC) and 'chance' (CHLC). In the study by Härkäpää et al (1991) HLC beliefs were associated with successful treatment outcome in LBP patients; patients with strong internal beliefs gained more from treatment and symptoms of psychological distress were significantly associated with poorer accomplishment of back exercises. Of importance was that the authors used the reliable change index, suggested by Jacobson et al (1984) for outcomes research, as a criterion of 'true' change (Härkäpää 1991).

Illness behaviour is believed to depend just as much on cognitive factors as on severity of pain or any physical impairment. Pain, particularly chronic pain, often leads to fear and avoidance behaviour, which in chronic pain is generally maladaptive (Waddell 1993). The Fear Avoidance Beliefs Questionnaire (FABQ) developed by Waddell (1993) provided strong evidence for fear-avoidance theory and is a reflection of the major cognitive, affective and behavioural pathways postulated between low back pain and disability. It is a useful outcome measure for evaluating the possible roles of cognitive, affective and behavioural factors linking pain, illness behaviour and disability (Waddell 1993). Recent prospective studies have demonstrated that high fear-avoidance beliefs are predictive of poor outcome in patients with acute non-specific LBP (Burton et al 1995; Klenerman et al 1995; Rose et al 1995).

Many studies of CLBP have failed to capture the multidimensional impact of the disease process or illness behaviour in a CLBP population. Outcomes research is an analysis of clinical practice as it actually occurs for the purpose of determining effectiveness of clinical methods (Dom-

\section{Figure 1: Three question depression screener (Levy et al 2002).}

37. In the past year, have you had 2 weeks or more during which you felt sad, blue, depressed or when you lost all interest in things that you usually cared about or enjoyed?

38. Have you had 2 years or more in your life when you felt depressed or sad most days, even if you felt okay sometimes?

39. Have you felt depressed or sad much of the time in the past year? 
holdt 2000) and has the potential to refine the quality of scientific inquiry into the effective management of LBP (Bardin 2002a). Liang et al (1994) suggest that in outcomes research the emphasis should be on the patient's assessment of pain, function, quality of life and satisfaction with the results of the intervention. It would appear important that evaluation of psychological impairment should be included in the documentation of outcomes relevant to CLBP.

\section{PATIENT SATISFACTION}

Patient satisfaction has become an important outcomes issue yielding valuable information about the quality of health care service as perceived by the patient (Deyo and Diehl 1986; Marks 1993 and 1994; Liang et al 1994; Stucki et al 1996; Liebenson and Yeomans 1997; Deyo et al 1998; Maher et al 1999; Bardin 1998, 2000a and 2000b; May 2001a; Beattie et al 2002; Monnin and Perneger 2002). Researchers have suggested that patient satisfaction with physiotherapy is emerging as an outcome variable of critical importance (Roush and Sonstroem 1999; Goldstein et al 2000). Patients reporting high satisfaction with care are more likely to be compliant with recommended treatment plans (including rehabilitation) and this might have particular relevance to the management of CLBP (Bardin 1998 and 2000b). A high level of dissatisfaction with medical care for back pain has been noted in research studies and consumer surveys (Deyo and Diehl 1986; Cherkin and MacCornack 1989). It has been suggested that one of the greatest challenges in the management of LBP is to gain a better understanding of back pain patients' needs and to use this information to assist health professionals to meet these needs (Cherkin 1998).

The patient's perceptions of the quality of the care delivered to them can be assessed by the following (Liebenson and Yeomans 1997):

- acceptance of care

- perception of the technical competence of a health care provider

- perceptions of the setting where care was provided

- perception of the effectiveness of the health care provider
Aspects of patient satisfaction are related to (Beattie et al 2002):

- Patient-practitioner relationship (competence, personality of the practitioner, communication)

- Location and accessibility of services

- Continuity of care

- Cost and payment issues

- Facilities (e.g. cleanliness, noise, equipment)

Because satisfaction can only be measured by asking the consumer directly, it has been suggested that the patient is the ultimate authority (Coulter 1994). Furthermore a satisfaction measure must be viewed in the context in which it will be used (Hudak and Wright 2000), in many cases standardised measures might not provide adequate data (Hudak and Wright 2000), and evaluation of satisfaction with outpatient physiotherapy may require a 'specialty-specific scale' (Beattie et al 2002).

By providing feedback, patients will actively contribute to quality improvement and to decision making in the healthcare arena (Deyo et al 1998; Ritchie 1999). Satisfaction does not always closely correlate with full resolution of symptoms (Greenfield et al 1975; Deyo and Diehl 1986; Fitzpatrick et al 1997) and it would appear that patients' judgments about the quality of care are based on more than the physiological outcome (May 2001a). In a recent study by May (2001b) patients' needs were found to relate not simply to the outcome of care, but also to the quality of the process of care.

Recent research by Beattie and colleagues focused on developing and testing an instrument used to determine which variables are associated with satisfaction of patients receiving outpatient physiotherapy (Beattie et al 2002). The researchers concluded that the instruments for measuring patient satisfaction developed by Roush and Sonstroem (1999) and by Goldstein et al (2000) both had good psychometric properties, however reflect different aspects of patient satisfaction and display a variation in content. The study by Beattie et al (2002) investigated which variables were most closely associated with overall satisfaction of patients receiving outpatient physiotherapy for occupation-related musculoskeletal conditions. Results of this study showed that patient satisfaction with care is most strongly correlated with the quality of the patient-therapist interactions (such as being treated with respect and being involved with treatment decisions) and that non-patient care issues (such as clinic location, equipment and parking) were less important in determining patient satisfaction.

Hudak and Wright (2000) noted that it is important to differentiate between patient satisfaction with care (relating to service during a course of care) and patient satisfaction with outcome (relating to the results of treatment). The instrument developed by Beattie et al (2002) was developed to assess patient satisfaction with care, and the authors acknowledge it is not adequate to measure satisfaction with outcomes. Their opinion is that overall assessment of outcome is a multidimensional task, which in addition to patient satisfaction with care, should also include other relevant measures such as health status, functional capacity and quality of life (Beattie et al 2002). This is consistent with the outcomes research model that has the potential to facilitate further research questions, the formulation of hypotheses and the planning of randomised, controlled trials, currently regarded as the gold standard of evidence (Bardin 2002a).

\section{HEALTH RELATED QUALITY OF LIFE}

The concept of HRQL, as defined by Jette (1993), is very broad, transcending narrower concepts such as functional limitation, disability or handicap, which are key elements of the disablement process that may be more familiar to physiotherapists (Jette 1993). Figure 2 illustrates how this concept of HRQL can be distinguished from the disablement process and how HRQL dimensions are broader than the corresponding disablement concepts. Health-related quality of life includes concepts at the personal or social level and does not include specific assessment of pathology, disease or impairments that are at the organ or body system level. The concept of HRQL addresses the consequences of disease and/or impairment as they affect 
Figure 2: The HRQL concept and the disablement process*

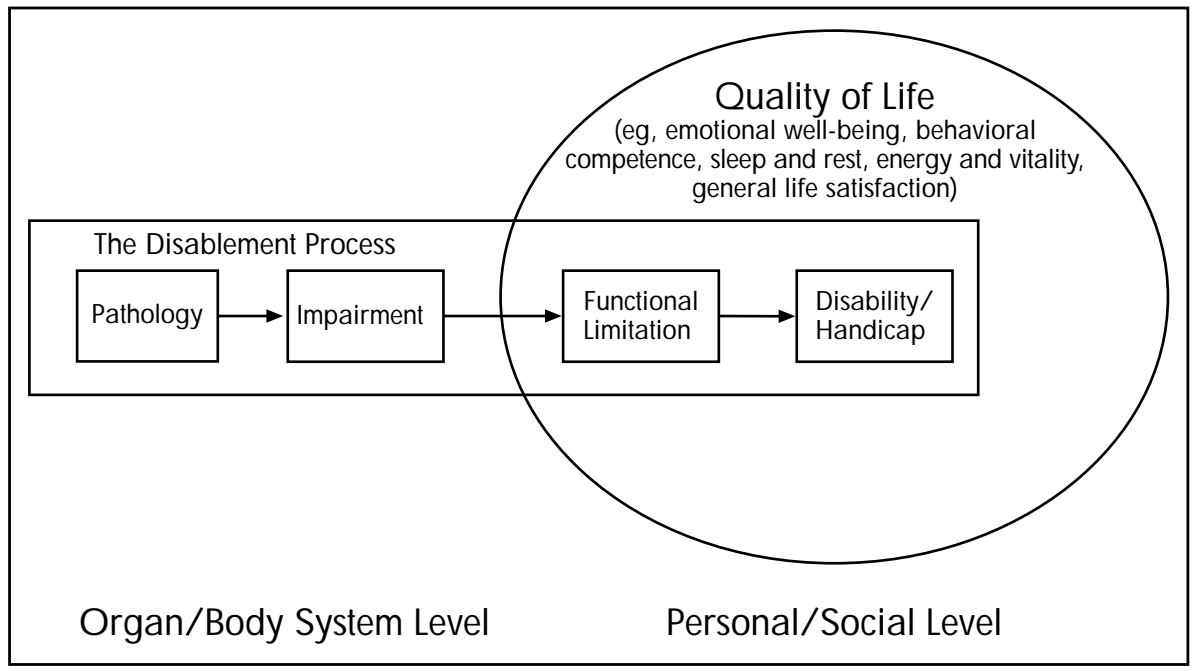

* Reproduced by kind permission of the American Physical Therapy Association from Jette AM (1993): Using health related quality of life measures in physical therapy outcomes research. Physical Therapy 73: 528-536

Figure 3: The three major dimensions and the elements in each dimension*

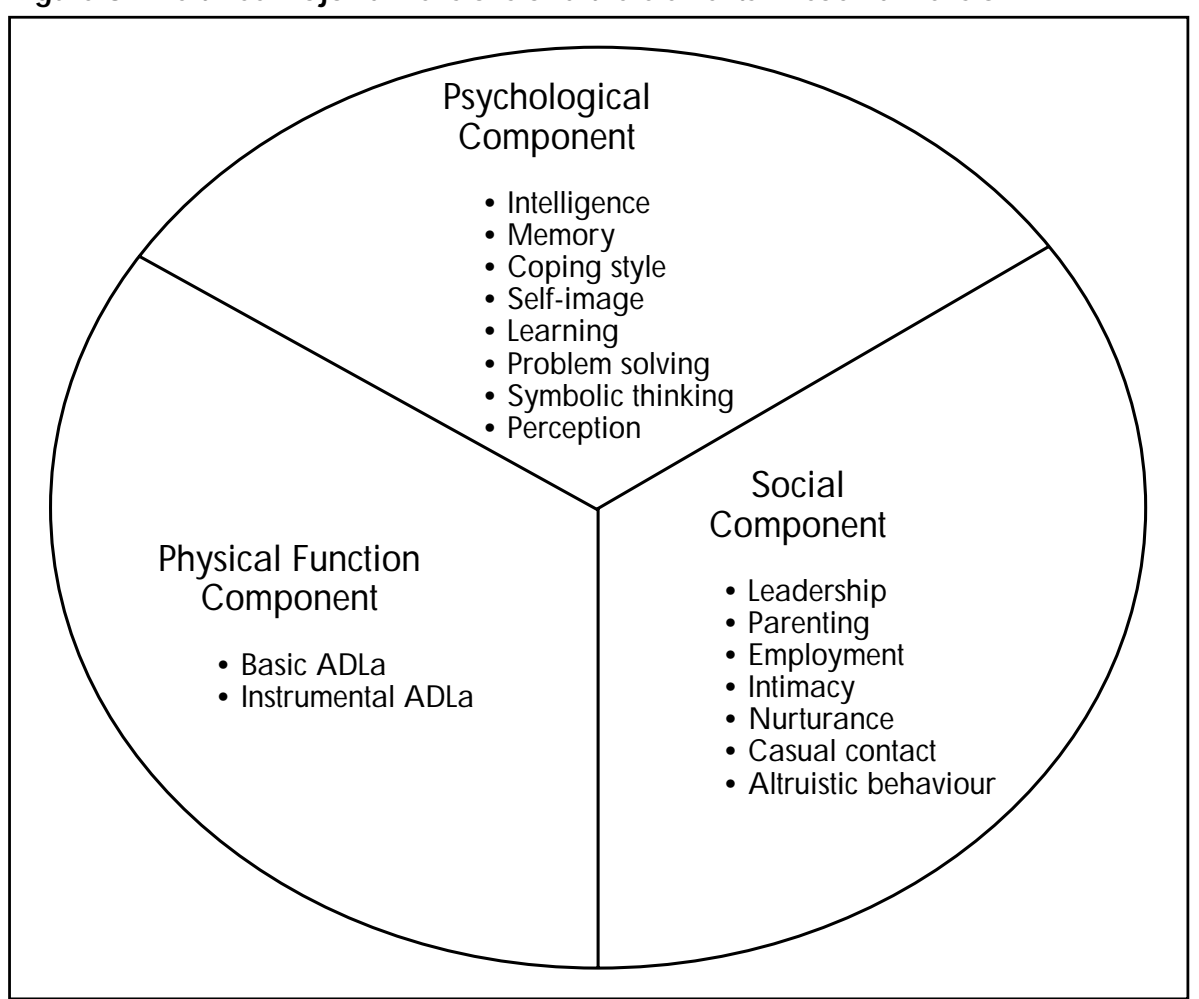

* Jette AM (1993): Using health related quality of life measures in physical therapy outcomes research. Physical Therapy 73: 528-536

the person at the personal or social level. Engel's biopsychosocial model (Engel 1982) provides a useful framework viewing HRQL as consisting of personand social-level components. The three major dimensions that have been described in the literature are illustrated in Figure 3 (Jette 1993). The physical function component encompasses the individual's performance of daily activities required to sustain oneself, for example basic ADL (such as dressing, bathing and walking) and instrumental ADL (more complex life activities, such as meal preparation, shopping and transportation). The psychological component consists of various cognitive, perceptual and personality traits of the individual, and the social component is viewed as the interaction of the individual within a larger social context (Jette 1993).

No gold standard exists for attributes such as pain and health-related quality of life (Stratford et al 2002) and in a recent study of 'health-related quality of life instruments', the authors raised concern over the variety and lack of standardisation of measurement tools for evaluating LBP (Zanoli et al 2000). They suggested that it would be very useful to be able to consistently compare baseline characteristics and treatment outcomes in patients who are seen by different spine professionals (Zanoli et al 2000). These authors, however, included pain and functional status questionnaires in their review of HRQL measures. Emotional well-being, overall life satisfaction, energy and vitality are all legitimate components of HRQL that are not traditionally included in definitions of functional limitations, disability and handicap (Jette 1993). The EuroQol instrument was developed to describe and value HRQL and it was hoped that this measure would lead to standardisation in the collection and reporting of HRQL data, complement other measures and facilitate the collection of a common data set for reference purposes (EuroQol Group 1990). It might be important to capture these aspects of low back dysfunction and Deyo et al (1998) recommend the use of the EuroQoL measurement (EuroQoL Group 1990) in their proposal for outcome measures for LBP research (Appendices I - IV of their publication). This would indicate a shift in focus to the personal/social level (Fig. 1), a distinct move to incorporate the biopsychosocial approach in outcomes research of LBP.

\section{CONCLUSION}

Measuring outcome of the management of LBP is a focus of attention that the physiotherapy profession needs to acknowledge and address (Bardin 2002a and 2002b). It has been suggested that a difficulty for the physiotherapy profession currently is demonstrating a specific cause and effect for many interventions because of inadequate research (Watson 1999). Outcome measures are an essential part of the documentation 
necessary for research in the field of LBP, both acute and chronic, and improved goal setting, patient motivation, good chart documentation and preliminary research/inquiry are all clear benefits that are likely to result from evaluation of outcomes management (Bardin 1998, 2002a and 2002b).

The opportunity exists for clinicians treating LBP patients to introduce a battery of outcome measures i.e. measures of functional and psychological status, patient satisfaction and health related quality of life to document change in the social and psychological and aspects of LBP patients' lives. These measures, together with biologic outcomes, reflect the biopsychosocial model necessary for evaluating the impact of LBP on a patient's life (Bardin 1998, 2000a and 2000c; Cherkin 1998; Deyo et al 1998). Objective outcome measures related to the biological component have been found to be only weakly correlated with patient behaviour or symptoms and the psychosocial and HRQL measures which assess multiple dimensions of life have been thought to be an inexpensive, valuable source of quantitative data for quality assurance and research of the LBP patient.

Documentation and analysis of outcomes will assist the physiotherapy profession to evaluate the relative effectiveness and cost-effectiveness of different interventions for LBP, to identify subgroups to be treated (Bardin 1998, 2000b and 2000c; O'Sullivan 2000) and to provide purchasers of healthcare with evidence of effectiveness (Chesson et al 1996; Watson 1999). Measuring the outcome of interventions for LBP, in particular CLBP, utilising appropriate, reliable and responsive outcome measures that reflect all the components of the biopsychosocial model (Bardin 2000a, 2000b and 2002b), is essential if physiotherapists are to advance their management of this disabling and costly condition, demonstrate their understanding of the multidimensional impact of LBP and contribute to the challenge of evidence-based practice.

\section{ACKNOWLEDGEMENT}

I should like to thank Dr. Nick Taylor, Senior Lecturer, Department of Physio- therapy, La Trobe University, Melbourne, for his encouragement and comments on the manuscript.

\section{REFERENCES}

Adams MA, Mannion AF, Dolan P 1999 Personal risk factors for first-time low back pain. Spine 24:2497-2505

Bardin LD 1998 A study to evaluate the effectiveness of a total back care programme for group rehabilitation of selected patients with chronic low back pain. M.Sc. Thesis, University of Stellenbosch, South Africa

Bardin LD 1999 A Spinal rehabilitation programme for selected patients with chronic/ recurrent low back pain: the results of a one year prospective study. Proceedings of the Congress of the South African Orthopaedic Association, Pretoria, South Africa, September 1999

Bardin LD 2000a Outcomes research of a spinal rehabilitation programme for chronic/ recurrent low back pain. Proceedings of the South African Spine Society, June, Cape Town, South Africa

Bardin LD 2000b A Spinal Rehabilitation Programme for selected patients with recurrent/chronic low back pain: a one year prospective study. Proceedings of the 7 th Scientific Conference of the International Federation of Orthopaedic Manipulative Therapists, Perth, Australia, November 2000

Bardin LD 2000c Spinal rehabilitation of chronic low back pain using patient education and group exercise therapy. Course manual, pre-conference course, 7th Scientific Conference of the International federation of Orthopaedic Manipulative Therapists, Perth, Australia, November, 2000

Bardin LD 2002a Physiotherapy and low back pain - Part I: Outcomes research in the quest for evidence. South African Journal of Physiotherapy 58:3-7

Bardin LD 2002b Physiotherapy and low back pain - Part II: Outcomes research utilising the biopsychosocial model: biological outcomes. South African Journal of Physiotherapy 58: 19-26

Bardin LD 2003 Physiotherapy management of accelerated spinal rehabilitation in an elite level athlete following L4-S1 instrumented spinal fusion. Physical Therapy in Sport 4: 41-46
Beattie PF, Pinto MB, Nelson MK, Nelson R 2002 Patient satisfaction with outpatient physical therapy: instrument validation. Physical Therapy 82:557-564

Beck AT, Ward J-C, Mendelson M, Mock J, Erbaugh J 1961 An inventory for measuring depression. Archives of General Psychiatry 4:561

Bigos SJ, Battie MC, Spengler DM, Fisher LD, Fordyce WE, Hanson TM, Nachemson AL, Wortley MD 1991 A prospective study of work perceptions and psychological factors affecting the report of back injury. Spine 16:1-6

Bouter LM, van Tulder MW, Koes BW 1998 Methodological issues in low back pain research in primary care. Spine 23:2014-2020

Brown J, Klapow J, Doleys D, Lowery D, Tutak U 1999 Disease-specific and generic health outcomes: a model for the evaluation of long-term intrathecal opoid therapy in non cancer low back pain patients. The Clinical Journal of Pain 15:122-131

Burton AK, Tillotson KM, Main CJ, Hollis S 1995 Psychosocial predictors of outcome in acute and subchronic low back trouble. Spine 20:722-728

Carey TS 1996 Disability in spinal stenosis: point of view. Spine 21:803

Cherkin DC, MacCornack FA 1989. Patient evaluations of low back pain care from family physicians and chiropractors. Western Journal of Medicine 150:35-355

Cherkin DC 1998. Primary Care Research on Low Back Pain. Spine 23:1997-2002

Chesson R, Macleod M, Massie S 1996 Outcome measures used in therapy departments in Scotland. Physiotherapy 82:673-679

Coulter ID 1994 The chiropractic satisfaction questionnaire. Topical Clinical Chiropractic $1: 40-43$

Croft PR, Papageorgoiu AC, McNally R 1997 Low back pain: Healthcare needs assessment. Radcliffe Medical Press, Oxford

Davidson M and Keating JL 2002 A comparison of five low back disability questionnaires: Reliability and responsiveness. Physical Therapy 82:8-24

Deyo RA, Diehl AK 1983 Measuring physical and psychosocial function in patients with low back pain. Spine 8:635-642 
Deyo RA, Diehl AK 1986 Patient satisfaction with medical care for low back pain. Spine 11:28-30

Deyo RA, Walsh NE, Schoenfeld LS, Ramamworthy S 1989 Studies of the modified somatic perceptions questionnaire (MSPQ) inpatients with back pain. Spine 14:507-510

Deyo RA, Andersson G, Bombardier C, Cherkin DC, Lee CK, Liang MH, Lipscomb B, Shekelle P, Spratt KF 1994 Outcome measures for studying patients with low back pain. Spine 19:2032S-2036S

Deyo RA, Battie M, Beurskens AJHM, Bombardier C, Croft P, Koes B, Malmivaara A, Roland M, Von Korff M, Waddell G 1998 Outcome Measures for Low Back Pain Research: a proposal for standardised use. Spine 23:2003-2013

Domholdt E 2000 Physical Therapy Research, 2nd edition, WB Saunders, Philadelphia

Engel GL 1982 Sounding board. The biopsychosocial model and medical education. Who are to be the teachers? New England Journal of Medicine 306:802-805

Feinstein AR, Josephy BR, Wells CK 1986 Scientific and clinical problems in indices of functional disability. Annals of Internal medicine 105:413-420

Fitzpatrick RM, Bury M, Frank AO, Donnelly T 1997 Problems in the assessment of outcome in a back pain clinic. International Disability Studies 9:161 - 165

Frost H, Lamb SE, Shackleton CH 2000 A functional restoration programme for chronic low back pain. Physiotherapy 86:285-293

Garratt AM, Moffett JK, Farrin AJ 2001 responsiveness of generic and specific measures of health outcome in low back pain. Spine 26:71-77

Goldberg DP and Hillier VF 1979 A scaled version of the General Health Questionnaire. Psychology Medicine 9:139-145

Goldberg D 1985 Identifying psychiatric illness among general medical patients British Medical Journal 291:161-162

Goldstein MS, Elliot SD, Guccione AA 2000 The development of an instrument to measure satisfaction with physical therapy. Physical Therapy 80:853-863
Greenfield S, Anderson H, Winickoff RN. Morgan A and Komaroff AL 1975 Nurse protocol management of low back pain: Outcomes, patient's satisfaction and efficiency of primary care. Western Journal of Medicine 123:350-359

Greenough CG, Fraser RD 1989 The effects of compensation on recovery from low back injury. Spine 14:947-955

Greenough CG, Fraser RD 1991 Comparison of eight psychometric instruments in unselected patients with back pain. Spine 16:1068-1074

Hagg O, Fritzell P, Anders O, Nordwall A and the Swedish Lumbar Spine Study Group 2002 Simplifying outcome measurement. Spine 27:1213-1222

Härkäpää K, Jarvikoski A, Mellin G, Murri H, Luoma J 1991 Health locus of control beliefs and psychological distress as predictors for treatment outcome in low back pain patients: results of a 3-month follow-up of a controlled intervention study. Pain 46:35-41

Hudak PL and Wright JG 2000 The characteristics of patient satisfaction measures. Spine 3167-3177

Huijbregts MPJ, Myers AM, Kay TM, Gavin TS 2002 Systematic outcome measurement in clinical practice:challenges experienced by physiotherapists. Physiotherapy Canada Winter 25-31

Jacobson NS, Follette WC, Revenstorf D 1984 Psychotherapy outcome research: methods for reporting variability and evaluating clinical significance. Behavior Therapy 15:336-352

Jette AM 1993 Using health related quality of life measures in physical therapy outcomes research. Physical Therapy 73:528-536

Jones M, Edwards I, Gifford L 2002 conceptual models for implementing biopsychosocial theory in practice. Manual Therapy 7:2-9

Klenerman L, Slade PD, Stanley IM 1995 The prediction of chronicity in patients with an acute attack of low back pain in a general practice setting. Spine 20:478-484

Kopec JA, Esdaile JM, Abrahamowicz M, Abenhaim L,wood-Dauphinee S, Lamping DL 1995 The Quebec Back Pain Disability Scale: measurement properties. Spine 20: 341352

Lansky D, Butler JBV, Waller FT 1992 Using health status measures in the hospital setting: from acute care to outcomes management. Medical Care 30:MS 57-73
Levy HI, Hanscom B, Boden SD 2002 Threequestion depression screener used for lumbar disc herniations and spinal stenosis. Spine 27:1232-1237

Liang MH, Andersson GBJ, Bombardier MD, Cherkin DC, Deyo MD 1994 Strategies for outcomes research in spinal disorders. Spine 19:2037S-2040S

Liang MH 2000 Longitudinal construct validity: establishment of clinical meaning in patient evaluative instruments. Medical Care 38:84-90

Liebenson C, Yeomans S 1997 Outcomes assessment in musculoskeletal medicine. Manual Therapy 2:67-74

Maher C, Latimer J, Refshauge K 1999 Prescription of activity for low back pain: what works? Australian Journal of Physiotherapy 45:121-132

Main CJ, Wood PL, Hollis S, Spanswich C, Waddell G 1992 The distress and risk assessment method (DRAM): a simple patient classification to identify distress and evaluate the risk of poor outcome. Spine 17:42-52

Mannion AF, Dolan P, Adams MA 1996 Psychological questionnaires: Do "abnormal" scores precede or follow first-time low back pain. Spine 21:2603-2611

Marks R 1993 Evaluating patient satisfaction: general considerations. New Zealand Journal of Physiotherapy 21:35-38

Marks R 1994 The development of a patient satisfaction questionnaire. New Zealand Journal of Physiotherapy 22:34-36

May SJ 2001a Patient satisfaction with management of back pain. Physiotherapy 87:4-9

May SJ 2001b An explorative, qualitative study into patients' satisfaction with physiotherapy. Physiotherapy 87:10-20

Mayer TG, Mooney V, Gatchel RJ, Barnes D, Terry A, Smith S, Mayer H 1989 Quantifying post-operative deficits of physical function following spinal surgery. Clinical Orthopaedics 244:147-157

McHorney CA, Ware JE, Rogers W, Raczek AE, Racel JF 1992 The validity and relative precision of MOS short and long-form health status scales and Dartmouth COOP charts. Medical care 30:M5253-265 
Million R, Hall W, Nilsen K, Baker R, Jayson M 1982 Assessment of the progress of the back pain patient. Spine 7:204-212

Monnin D and Perneger TV 2002 Scale to measure patient satisfaction with physical therapy. Physical Therapy 82:682-691

Moore A and Jull G 2002 Reflections on the musculoskeletal therapist's multifaceted role influences on treatment outcomes. Manual Therapy 7: 119-120

O'Sullivan PB 2000 Lumbar segmental 'instability': clinical presentation and specific stabilising exercise management. Manual Therapy 5:2-12

Partridge CJ 1984 Recovery from conditions involving physical disability. Physiotherapy 70:233-235

Riddle DL and Stratford PW 2002 RolandMorris Scale Reliability: letter to the Editor. Physical Therapy 82:512-514

Ritchie JE 1999 Using qualitative research to enhance the evidence-based practice of health care providers. Australian Journal of Physiotherapy 45: 251-256

Roland M, Morris R 1983a A study of the natural history of back pain. Part I: Development of a reliable and sensitive measure of disability in low back pain. Spine 8:141-144

Roland M, Morris R 1983b A study of the natural history of back pain part II: development of guidelines for trials of treatment in primary care. Spine 8:145-150

Rose M, Reilly J, Slade P, Dewey M 1995 A comparative analysis of psychological and physical models of low back pain experience. Physiotherapy 81:710-716

Rost K, Burnam MA, Smith GR 1993 Development of screeners for depressive disorders and substance disorder history. Medical Care 31:189-220

Rothstein JM 2001 Impairments: Always linked to meaningful disability? Physical Therapy 886-887

Roush SE, Sonstroem RJ 1999 Development of the Physical Therapy Outpatient Satisfaction Survey (PTOPS). Physical Therapy 79:159-170

Ruta DA, Garratt AM, Wardlaw D, Russell IT 1994 Developing a valid and reliable measure of health outcome for patients with low back pain. Spine 19:1887-1896
Streiner GL, Norman DR 1995 Health measurement scales: a practical guide to their development and use. Oxford: Oxford University Press.

Stratford PW, Binkley J, Solomon P, Gill C, Finch E 1994 Assessing change over time in patients with low back pain. Physical Therapy 74:528-533

Stratford PW, Gill C, Westaway M, Binkley J 1996 Defining the minimum level of detectable change for the Roland-Morris Questionnaire. Physical Therapy 76:359-365

Stratford PW and Binkley JM 1997 Measurement properties of the RM-18. Spine 22:2416-2421

Stratford PW and Binkley JM 2000 A comparison study of the Back Pain Functional Scale and Roland Morris Questionnaire. The Journal of Rheumatology 27:1928-1936

Stratford PW, Binkley JM, Riddle DL 2000 Development and initial validation of the Back Pain Functional Scale. Spine 25: 20952102

Stratford PW, Spadoni, Kennedy D, Westaway MD, Alcock GK 2002 Seven points to consider when investigating a measure's ability to detect change. Physiotherapy Canada 54: 16-24

Stucki G, Daltroy L, Liang M, Lipson S, Fossel A, Katz JN 1996 Measurement properties of a self-administered outcome measure in lumbar spinal stenosis. Spine 21:796-803

Taimela S, Kujala UM, Salminem JJ, Viljanen T 1997 The prevelance of low back pain among children and adolescents: A nationwide, cohort-based questionnaire survey in Finland. Spine 22:1132-1136

Volinn E, van Koevering D, Loeser JD 1991 Back sprain in industry: the role of socioeconomic factors in chronicity. Spine 16:542-548

Waddell G, Main CJ 1984 Chronic low back pain psychologic distress and illness behaviour. Spine 9:204-208

Waddell G, Newton M, Henderson I, Somerville D, Main CJ 1993 A fear-avoidance beliefs questionnaire (FABQ) and the role of fear-avoidance beliefs in chronic low back pain and disability. Pain 52:157-168

Wallston BS, Wallston KA, Kaplan GD, Maides SA 1976 Development and validation of the health Locus of Control (HLC) scale. Journal of consulting and clinical psychology 44:580-585
Wallston KA, Wallston BS, DeVellis R 1978 Development of the Multidimensional Health Locus of Control (MHLC) scales. Health Education Monograph 6:160-170

Walsh T 2000 The Oswestry Disability Index: point of view. Spine 25:2953

Ware J 1987 Standards for validating health measures: definition and content. Journal of chronic diseases 40:473-480

Ware JE, Sherbourne CD 1992 The MOS 36Item Short-Form Health Survey (SF-36): conceptual framework and item selection. Medical care 30:473-483

Watson PJ 1999 Psychosocial Assessment. Physiotherapy 85:530-535

Wesley AL, Gatchel RJ, Garofalo JP, Polatin PB 1999 Towards more accurate use of the Beck Depression Inventory with chronic back pain patients. Clinical journal of pain 15: 117-121

WHO, ICF 2001 World Health Organisation, International classification of Functioning, Disability and Health, Geneva

Zanoli G, Stromqvist B, Padua R, Romanini E 2000 Lessons learned searching for a HRQoL instrument to assess the results of treatment in persons with lumbar disorders. Spine 25: 3178-3185

Zung WWK 1965 A self-rating depression scale. Archives of General Psychiatry 12:63-70 